\title{
Predictive Indicators of Overuse Injuries in Adolescent Endurance Athletes
}

\author{
Daniel Martínez-Silván, Jaime Díaz-Ocejo, and Andrew Murray
}

\begin{abstract}
Purpose: To analyze the influence of training exposure and the utility of self-report questionnaires on predicting overuse injuries in adolescent endurance athletes. Methods: Five adolescent male endurance athletes (15.7 $\pm 1.4 \mathrm{y})$ from a full-time sports academy answered 2 questionnaires (Recovery Cue; RC-q and Oslo Sports Trauma Research questionnaire; OSTRC-q) on a weekly basis for 1 season (37 wk) to detect signs of overtraining and underrecovery (RC-q) and early symptoms of lower-limb injuries (OSTRC-q). All overuse injuries were retrospectively analyzed to detect which variations in the questionnaires in the weeks preceding injury were best associated. Overuse incidence rates were calculated based on training exposure. Results: Lower-limb overuse injuries accounted for $73 \%$ of total injuries. The incidence rate for overuse training-related injuries was 10 injuries $/ 1000 \mathrm{~h}$. Strong correlations were observed between individual running exposure and overuse injury incidence $\left(r^{2}=\right.$ $.66)$, number of overuse injuries $\left(r^{2}=.69\right)$, and days lost $\left(r^{2}=.66\right)$. A change of $20 \%$ or more in the RC-q score in the preceding week was associated with $67 \%$ of the lower-limb overuse injuries. Musculoskeletal symptoms were only detected in advance by the OSTRC-q in $27 \%$ of the episodes. Conclusion: Training exposure (especially running exposure) was shown to be related to overuse injuries, suggesting that monitoring training load is a key factor for injury prevention. Worsening scores in the RC-q (but not the OSTRC) may be an indicator of overuse injury in adolescent endurance runners when used longitudinally.
\end{abstract}

Keywords: injury management, endurance training, sport medicine.

The ability to detect and prevent injuries early remains one of the big challenges in sport. Although some injuries may be unpredictable and therefore difficult to prevent, most of the injuries related to long-distance running have an origin in excessive loads and a history of overuse. ${ }^{1}$ This suggests that training-load monitoring and early detection may be effective in aiding injury prevention.

The literature on injury epidemiology in adolescent track and field athletes is scarce, but runners seem to account for the majority of injuries (up to $80 \%{ }^{2}$ ) with the majority of these injuries (more than two-thirds ${ }^{3}$ ), occurring in the lower extremity and being of an overuse nature. ${ }^{1}$ Although incidence rates in senior athletics has been reported as 3.9 injuries/1000 h of practice, ${ }^{4}$ specific injury incidence in youth track and field varies among disciplines; whereas an overall incidence of 0.89 injuries/1000 $\mathrm{h}$ has been reported for high school track and field athletes, long-distance runners have showed a 19 times larger incidence $(17 \text { injuries/1000 h) })^{5}$ than disciplines. Due to the gradual onset of most overuse injuries new methods, by means of self-reported questionnaires, have been suggested for registering overuse injuries in epidemiological studies in athletics, which may currently be underestimated. ${ }^{6}$

The purpose of this study is to establish the relationship between specific training exposures (running) and overuse injuries, as well as the utility of 2 self-reported questionnaires on the early detection of overuse conditions in a squad of highly trained adolescent distance runners.

The authors are with the Aspire Health Center, Aspire Academy, Doha, Qatar. Address author correspondence to Daniel Martínez-Silván at daniel. silvan@aspetar.com.

\section{Methods}

\section{Subjects}

A group of 5 male adolescent middle-distance athletes $(15.7 \pm 1.4 \mathrm{y}$, $174.2 \pm 3.2 \mathrm{~cm}, 54.2 \pm 4.4 \mathrm{~kg}, 60.2 \pm 5.0 \mathrm{~mL} \cdot \mathrm{kg}^{-1} \cdot \mathrm{min}^{-1}$ ) enrolled in a full-time sports academy participated in the study during the 2014-15 season. All athletes were training up to a maximum of 9 sessions $(\sim 18 \mathrm{~h})$ a week. The local ethics committee approved the procedures and the parents signed the informed consent.

\section{Methodology}

A retrospective cohort study design was employed to establish the relationship between training exposures and overuse injuries, as well as the utility of 2 weekly self-report questionnaires to detect early signs of overuse injuries.

\section{Data Analysis}

Injury data from the 2014-15 season (September 2014 to June 2015), were reviewed for this group and analyzed according to criteria of injury type, site and origin, ${ }^{7}$ and a comparison with the whole athletics squad (51 athletes of different disciplines) was stablished.

Any musculoskeletal condition requiring medical attention was recorded and both injuries ( $>1 \mathrm{~d}$ loss of training) and complaints (requiring treatment but no training loss) were analyzed. According to the consensus statement for injury and illness data collection in athletics, ${ }^{7}$ studies applying only a time-loss definition can miss a large share of overuse conditions, so when incidence rates (number of injuries/1000 h exposure) were calculated in this study, both training loss and nontraining loss injuries were used. Prevalence of overuse injuries was also calculated. 
Sport-specific (running) and total training exposure (including gym, testing and others) were calculated for each athlete based on training attendance over the season, with session duration standardized in length for the purposes of analysis as 75 minutes for track-specific sessions, 60 minutes for run sessions, and 45 minutes for strength and conditioning. Values were expressed in hours as mean \pm SD.

During the whole season, this group of athletes filled out 2 questionnaires on a weekly basis: RC-q and OSTRC-q. The RC-q is a 7-item recovery protocol which attempts to measure current stress and recovery states. It was developed in an effort to monitor early warning signs of possible overtraining effects (perceived exertion, perceived recovery and recovery effort), and recovery processes (physical recovery, sleep quality, social recovery, and self-regulation). A final average score on a scale of 1 to 7 (lower score being better) was calculated for every athlete on a weekly basis. When analyzing the RC-q results for the study, items 1 to 4 were analyzed together as overtraining (OT) signs, and items 5 to 7 as underrecovery (UR) signs.

The OSTRC- $\mathrm{q}^{9}$ consists of four items for pain or limitations in performance during the past week, due to problems in 3 lower-limb regions; hip, knee/thigh, and foot/ankle/lower leg. A final score from 0 (no complaints) to 100 (unable to train) was calculated for every athlete on a weekly basis.

Both questionnaires were administered in English and backtranslated into Arabic, (as the athletes were native Arabic speakers but had a proficient level of English).

To establish the utility of the questionnaires to detect early signs that may develop into overuse injuries, every lower-limb overuse injury was selected for further analysis and the results of the questionnaires reviewed to look for significant changes before each injury was reported. RC-q results were expressed as a percentage of the maximum score, and the variation of the OT and UR scores was studied, reporting the percentage of variation in the 2 weeks before every overuse episode and selecting the most significant 1 for further study. For the OSTRC-q, any score $>0$ in any of the previous 2 weeks, indicating a lower limb musculoskeletal complaint impairing performance was analyzed to look for potential relationship with overuse injuries.

\section{Statistical Analysis}

Coefficients of correlation ( $r$ and $r^{2}$ ) between individual training exposure and number of overuse injuries, total days lost due to injuries, overuse injury incidence, and specific training incidence were calculated. Prevalence of injuries with significant changes in the questionnaires was calculated. For OSTRC-q, any score $>0$, meaning any physical complaint impairing performance was considered significant, whereas for RC-q, due to the lack of an established cutoff point, a retrospective variation threshold of $20 \%$ was established.

\section{Results}

Looking at injury type (overuse vs traumatic) a higher percentage of overuse episodes were seen in the endurance team $(76 \%)$ than in the whole squad (48\%), with most injuries (79\%) being sustained in the lower limbs, and related to training in $88 \%$ of the cases.

When analyzing data from the subjects included in the study, 22 medical attentions were recorded during the entire season (4.4 episodes/athlete), with a $68 \%$ prevalence of lower-limb injuries related to overuse, most of them (67\%) injuries with more than 1 day loss (mean $=3.5 \mathrm{~d}$; Table 1$)$.

Athletes had a mean training exposure of $318.7 \pm 10.7$ hours, of which $88 \%$ were sport specific (running) and the incidence rate for lower-limb overuse running-related episodes was 10/1000 $\mathrm{h}$ of practice. A very strong correlation $\left(r=.83 ; r^{2}=.69\right)$ was observed between the number of overuse episodes and the individual running exposure, between the running exposure and the total number of days lost due to overuse episodes $\left(r=.81 ; r^{2}=.66\right)$, and between lower-limb overuse injury incidence and total running exposure $(r$ $=.81 ; r^{2}=.66$ ), whereas if only time-loss injuries were considered for incidence rates, a lower moderate correlation was found ( $r=$ .61 ; Figure 1).

Analyzing the RC-q longitudinally ahead of each injury episode, increasing signs of OT or UR (increased variation) was seen ahead of most episodes. Two-thirds of overuse-related musculoskeletal conditions (67\%) showed signs of OT or UR in advance at the $20 \%$ threshold. An OSTRC-q score $>0$ was only seen in the previous week in $27 \%$ of cases (Table 2), which shows a weak ability of the OSTRC-q to detect injuries in advance.

\section{Discussion}

Lower-limb overuse injuries are of large concern in endurance running. ${ }^{1}$ The purpose of this study was to establish the relationship between specific training exposures and overuse injuries, as well as the utility of 2 self-report questionnaires in highly trained adolescent distance runners.

This group showed a very high prevalence and incidence of overuse injuries. According to the latest recommendations, this

Table 1 Complete Data of Injuries, Exposure, and Injury Incidence in the Study Group

\begin{tabular}{|c|c|c|c|c|c|c|c|c|c|}
\hline Athlete & Age, y & $\begin{array}{l}\text { Incidence } \\
\text { of medical } \\
\text { attention (n) }\end{array}$ & $\begin{array}{l}\text { Lower-limb } \\
\text { overuse } \\
\text { episodes (n) }\end{array}$ & $\begin{array}{l}\text { Overuse } \\
\text { injuries } \\
\text { (training } \\
\text { loss) }\end{array}$ & $\begin{array}{c}\text { Overuse } \\
\text { complaints } \\
\text { (no training } \\
\text { loss) }\end{array}$ & $\begin{array}{c}\text { Days lost } \\
\text { 2014-15 (n) }\end{array}$ & $\begin{array}{l}\text { Running } \\
\text { exposure } \\
\text { (h) }\end{array}$ & $\begin{array}{l}\text { Total training } \\
\text { exposure }(\mathrm{h})\end{array}$ & $\begin{array}{l}\text { Running lower-limb } \\
\text { overuse incidence } \\
\text { (injuries/1000 h) }\end{array}$ \\
\hline A & 18.0 & 7 & 4 & 2 & 2 & 6 & 278 & 307 & 14.39 \\
\hline B & 15.9 & 9 & 6 & 3 & 3 & 14 & 293 & 338 & 20.48 \\
\hline $\mathrm{C}$ & 15.4 & 1 & 1 & 1 & 0 & 1 & 272 & 312 & 3.68 \\
\hline D & 15.4 & 1 & 0 & 0 & 0 & 0 & 277 & 316 & 0.00 \\
\hline $\mathrm{E}$ & 14.4 & 4 & 4 & 4 & 0 & 15 & 282 & 320 & 14.18 \\
\hline $\begin{array}{l}\text { Total or } \\
\text { average }\end{array}$ & 15.7 & 22 & 15 & 10 & 5 & 36 & 280.4 & 318.6 & 10.55 \\
\hline
\end{tabular}




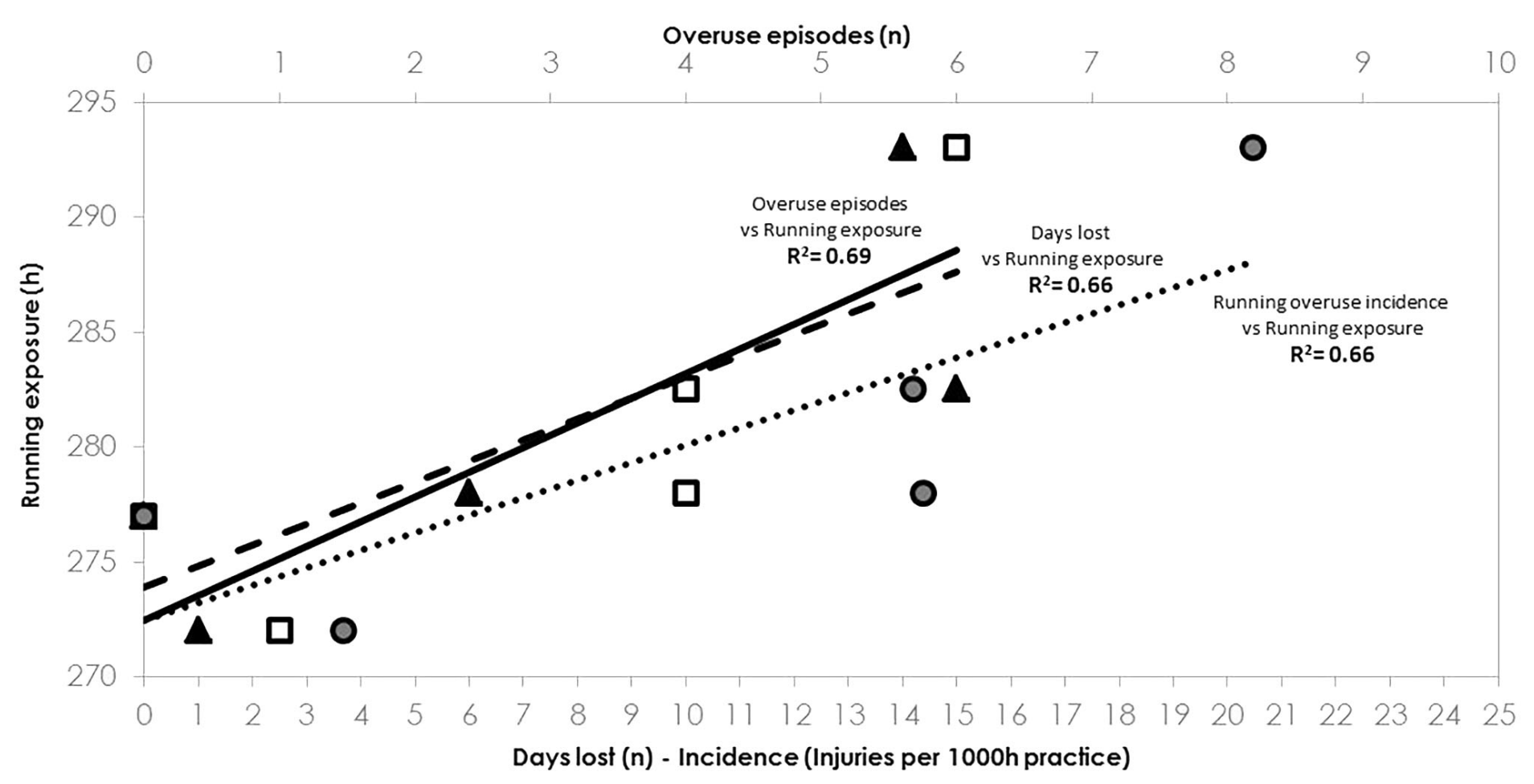

$\Delta$ Days lost (n)

ORunning overuse incidence

口Overuse episodes

Figure 1 - Individual running exposure in relation to lower-limb overuse incidence, total days lost, and number of overuse episodes, with trend lines showing correlations and $R^{2}$ values between running exposure and the different variables.

Table 2 Analysis of Questionnaires' Score Variation Ahead of Each Injury

\begin{tabular}{llccc}
\hline ID-injury number & Description & \% variation OT score & \% variation UR score & OSTRC $>0$ \\
\hline A1 & Medial tibial stress & $51 \%$ & $32 \%$ & no \\
A2 & Anterior knee pain & $33 \%$ & $-25 \%$ & no \\
A3 & Achilles tendinopathy & $-15 \%$ & $-4 \%$ & no \\
A4 & Plantar fasciitis & $24 \%$ & $7 \%$ & yes \\
B1 & Osgood Schlatter disease & $\mathrm{n} / \mathrm{a}$ & $\mathrm{n} / \mathrm{a}$ & no \\
B2 & AIIS apophysitis & $33 \%$ & $29 \%$ & no \\
B3 & Achilles tendinopathy & $-5 \%$ & $4 \%$ & yes \\
B4 & Calf DOMS & $39 \%$ & $7 \%$ & yes \\
B5 & Hamstrings DOMS & $20 \%$ & $25 \%$ & no \\
B6 & Hamstrings DOMS & $\mathrm{n} / \mathrm{a}$ & $22 \%$ & yes \\
C1 & ASIS apophysitis & $14 \%$ & $35 \%$ & no \\
E1 & Ischion apophysitis & $29 \%$ & $-3 \%$ & no \\
E2 & ASIS apophysitis & $20 \%$ & $-14 \%$ & no \\
E3 & Pelvic/glut pain & $-10 \%$ & $43 \%$ & no \\
E4 & Patellar apophysitis & $24 \%$ & & \\
\hline
\end{tabular}

study shows that training loss injuries should not be considered alone when calculating incidence and prevalence rates in athletics. A week-to-week increase of more than $20 \%$ in the OT and/or UR scores of the RC-q was shown to be related to a large proportion of overuse injuries, therefore it can be suggested as a good reference point for injury prevention purposes, although studies with larger samples are needed. Despite having shown to be a good tool for recording overuse injuries in epidemiological studies in individual sports ${ }^{10}$ the OSTRC was not useful for the early detection of overuse injuries in this group of adolescent endurance athletes. 
In spite of recent investigations suggesting that the balance of recent ( $7 \mathrm{~d})$ and historical $(28 \mathrm{~d})$ workloads may be more related to injuries than training exposure by itself, ${ }^{10}$ this study has shown that specific training exposure is strongly correlated with lowerlimb overuse injuries in this small sample of adolescent endurance athletes. One of the limitations of this study is that training intensity was not recorded, so individual training load data could not be used for the study. Whereas it seems clear that more exposure to running across a whole season was related to more overuse episodes, it must be noted when interpreting the data that most of the injuries reported were mild (ie, minimal or no time loss). Whether this was a result of the musculoskeletal adaptations to training or a sign of overtraining/under recovery remains unclear, but given the musculoskeletal vulnerability of adolescent athletes to repetitive loads, it has been suggested that training programs should be modified to accommodate differences in training ages. ${ }^{11}$

The RC-q seems to be a useful tool to monitor internal load when the results are interpreted longitudinally. As excessive and rapid increases in training loads are likely responsible for a large proportion of overuse injuries ${ }^{10}$ and training exposure is not an effective method to detect them, self-report scores may be a sensitive tool for injury prevention.

While the OSTRC-q does not seem effective for early detection of overuse injury, this does not mean that any pain or complaint reported in the questionnaire must be disregarded, but only around $25 \%$ of overuse injuries recorded showed symptoms previously via the questionnaire. The reason for this may be that full-time academy athletes have access to medical staff frequently, so any "serious" injury can be detected early without need for a questionnaire.

\section{Practical Applications}

Total running exposure maybe a good indicator for overuse injury risk in adolescent endurance athletes. The RC-q administered weekly has shown to be a good predictor for injury when a change of more than $20 \%$ in the OT or UR score is observed.

The main limitation of this study is the small sample size. Similar studies with larger group samples would be interesting.

\section{Conclusions}

Lower limb overuse injuries are the main concern in distance running, but this type of injury might benefit more from a training-loadmonitoring-based injury-prevention program. Easy and practical information should be used to avoid time-consuming data analysis, and for that purpose a single measure of external training load (running exposure) and another for internal training load (RC-q) seem to be useful for overuse injury prevention.

\section{References}

1. Bennell KL, Crossley K. Musculoskeletal injuries in track and field: incidence, distribution and risk factors. Aust J Sci Med Sport. 1996;28(3):69-75. PubMed

2. Tyflidis A, Kipreos G, Tripolitsioti A, Stergioulas A. Epidemiology of track \& field injuries: a one year experience in athletic schools. Biol Sport. 2012;29(4):291-295 doi:10.5604/20831862.1019885.

3. Zemper ED. Track and field injuries. Med Sport Sci. 2005;48:138-151 doi:10.1159/000084287. PubMed

4. Pierpoint LA, Williams CM, Fields SK, Comstock RD. Epidemiology of injuries in United States high school track and field: 2008-2009 through 2013-2014. Am J Sports Med. 2016;44(6):1463-1468. doi:10.1177/0363546516629950 PubMed

5. Rauh MJ, Koepsell TD, Rivara FP, Margherita AJ, Rice SG. Epidemiology of musculoskeletal injuries among high school cross-country runners. Am J Epidemiol. 2006;163(2):151-159 doi:10.1093/aje/ kwj022. PubMed

6. Bahr R. No injuries, but plenty of pain?: on the methodology for recording overuse symptoms in sports. Br J Sports Med. 2009;43(13):966-972 doi:10.1136/bjsm.2009.066936. PubMed

7. Timpka T, Alonso J-M, Jacobsson J, et al. Injury and illness definitions and data collection procedures for use in epidemiological studies in athletics (track and field): consensus statement. Br J Sports Med. 2014;48(7):483-490 doi:10.1136/bjsports-2013-093241. PubMed

8. Kellmann M, Patrick T, Botterill C, Wilson C. The recovery-cue and its use in applied settings: practical suggestions regarding assessment and monitoring of recovery. In: Kellmannn M, ed. Enhancing Recovery: Preventing Underperformance in Athletes. Champaign, IL: Human Kinetics; 2002:219-229.

9. Clarsen B, Myklebust G, Bahr R. Development and validation of a new method for the registration of overuse injuries in sports injury epidemiology: the Oslo Sports Trauma Research Centre (OSTRC) Overuse Injury Questionnaire. Br J Sports Med. 2013;47(8):495-502 doi:10.1136/bjsports-2012-091524. PubMed

10. Gabbett TJ. The training-injury prevention paradox: should athletes be training smarter and harder? Br J Sports Med. 2016;50(5):273-280. doi:10.1136/bjsports-2015-095788 PubMed

11. Gabbett TJ. Performance changes following a field conditioning program in junior and senior rugby league players. $J$ Strength Cond Res. 2006;20(1):215-221. doi:10.1519/R-16554.1 PubMed 